\title{
The Effect of Using Human Patient Simulation on Undergraduate Nursing Student Skill Performance and Anxiety Level
}

\author{
Ali Mohammed Husien * Radhwan Husien Ibrahim **
}

\begin{abstract}
Background and Aim Human patient simulators provide a very realistic situation for nursing students, centers on the opportunity for the learner to practice and learn in an environment as close to reality as possible, allows students to construct knowledge, explore assumptions, and develop psychomotor skills in a safe environment. The study aims to assess the effect of using human patient simulation on undergraduate nursing students' skill performance and anxiety levels at the college of Nursing in Mosul University.
\end{abstract}

Method and Materials: A case control study design has been used for the 1st February 2014 till 30th of May 2014. A non-probability convenience sampling of (90) under graduate nursing students (60) females and (30) males were chosen, the study sample was divided into two groups, an experimental group of (45) nursing students with human patient simulation laboratory setting experience and control group of (45) nursing students with clinical practice setting experience. The validity of this study instruments was established through a panel of (12) experts of different specialties related to the field of the present research, Reliability of the study tools was determined through the use of split half -approach of the computation of Cronbach alpha correlation coefficients for the checklist and The Cronbach's alpha for the questionnaire. Data collection tools include the checklist which is consisted of (25) question items that related to the physical examination for thorax and lungs and the questionnaire consisted of (15) question items respondents were asked to rate the individual items on a (5)-point scale according to their response to each item, Data were prepared and entered into a computer files; Statistical Package for the Social Science (SPSS, version 21) is used for data analysis.

Conclusions: The study result show that there is a significant effect of simulation in Students' skills performance level while there is no effect in control group, and there is a significant relationship between students' skill performance and gender for case group, while there were no significant relationship between students' skill performance and gender for control group. The male students is more improvement than female in their skill level after simulation course. Anxiety level were higher in student who apply physical examination on a patient comparing with those students who apply physical examination on a HPS.

Recommendation: The study recommended to introduce the modern technology (HPS) in students' training process because it decrease students' anxiety level so the skill performance of students will be more confident and reduce errors when skilled nursing application and thus reflected repercussions on public health and a better way than the old classical training.

Keywords: Effect, Simulation, skill, Anxiety, Nursing Student.

\section{INTRODUCTION}

Nurse Educators need to find adequate clinical experiences for their students. However, there is a limited clinical placements that provide opportunities for clinical experiences with real patients (Yuan et al., 2011). Clinical nurse educators struggled to find facilitating raining experiences to prepare students for such practice demands (NCSBN, 2009). In addition, nurse educators are interested in expanding teaching, learning methods to assist nursing students and develop safe nursing clinical practice. Nowadays, nursing education is changing because the advancing of technology used in different training settings, Human Patient Simulators (HPS) is one of the technological devices that increasingly used in nursing education systems (Yuan et al., 2011).Human patient simulators provide a very realistic situation for nursing students. Simulation, a largely risk free approach to learning, centers on the opportunity for the learner to practice and learn in an environment as close to reality as possible, allows students to construct knowledge, explore assumptions, and develop psychomotor skills in a safe environment (Garrett et al., 2010). Simulation technology has been utilized into nursing education to support the development of nurses' clinical performance in assessing and managing uncommon and emergent clinical situations. Simulation is "as a strategy - not only a technology, to mirror, anticipate, or amplify real situations with guided

\footnotetext{
* MSc Candidatel Nineveh Health Directorate .

** Professor/ College of Nursing/ University of Mosul .
} 
experiences in a fully interactive way" (Partin $e t$ al., 2006).

\section{MATERIALS AND METHOD}

A case control study design has been used for the $1^{\text {st }}$ February 2014 till $30^{\text {th }}$ of May 2014 in the University of Mosul, College of Nursing, Clinical Nursing Science department; human patient simulation laboratory. A non-probability convenience sampling of (90) undergraduate nursing students (60) females and (30) males were chosen, the study sample were divided into two groups, an experimental group of (45) nursing students with human patient simulation laboratory setting experience and control group of (45) nursing students with clinical practice setting experience. The study tools include the checklist which is consisted of (25) question items that related to the physical examination for thorax and lungs by Observational method were used to assess the skill performance for undergraduate nursing student and the checklist constructed when extensive review of the related and previous studies. The question items were rated and scored according to Likert scale (2) correctly performed, (1) incorrectly performed, (0) not performed; To fulfill it, each RESULTS interview with each participant lasted a period of time between 10-15 minutes. But the second tool is The questionnaire (Anxiety Level Questionnaire) consisted of (15) question items respondents were asked to rate the individual items on a 5-point scale according to their response to each item. The scale responses were (1) Very confident, (2) confident, (3) Neutral, (4) anxious, and (5) Very Anxious. The validity of this study instrument was established through a panel of (12) experts of different specialties related to the field of the present research, Reliability of the study tools was determined through the use of split half -approach of the computation of cronbach alpha correlation coefficients for the checklist and The Cronbach's alpha for the questionnaire. The outcomes were 0.82 and 0.923 for the for the checklist and for the questionnaire respectively. The data were analyzed using the statistical package for social science (SPSS) program version 17 throughout the application of descriptive statistic (frequency, mean, standard deviation and percentage) and inferential statistics (Chi - Square, Basic pooled t-test.

Table (1): Comparison between patient and simulation according to gender.

\begin{tabular}{|l|c|c|c|c|c|c|}
\hline \multirow{2}{*}{ Gender } & \multicolumn{2}{|c|}{ Patient } & \multicolumn{2}{c|}{ simulation } & \multicolumn{2}{c|}{ Total } \\
\cline { 2 - 7 } & No & $\%$ & No & $\%$ & No & $\%$ \\
\hline Male & 15 & $33 \%$ & 15 & $33 \%$ & 30 & $33 \%$ \\
\hline Female & 30 & $67 \%$ & 30 & $67 \%$ & 60 & $67 \%$ \\
\hline Total & 45 & $100 \%$ & 45 & $100 \%$ & 90 & $100 \%$ \\
\hline
\end{tabular}

Table (2): Comparison between Pretest and posttest of performance skill for experimental group.

\begin{tabular}{|c|c|c|c|c|c|c|c|c|}
\hline \multirow{2}{*}{ Gender } & \multirow{2}{*}{ No. } & \multicolumn{3}{|c|}{ Mean } & \multirow{2}{*}{ Sta. Dev. } & \multirow{2}{*}{ T cal. } & \multirow{2}{*}{ T tab. } & \multirow{2}{*}{ Sig. } \\
\hline & & Pre & Post & Deferens & & & & \\
\hline Male & 15 & 22.4667 & 33.0667 & 10.6000 & 3.86929 & 10.610 & $\begin{array}{c}2.145 \\
(0.05)(14)\end{array}$ & 0.000 \\
\hline Female & 30 & 22.5333 & 30.4000 & 7.8667 & 5.29628 & 8.135 & $\begin{array}{c}2.045 \\
(0.05)(29)\end{array}$ & 0.000 \\
\hline Total & 45 & 22.5111 & 31.2889 & 8.7778 & 4.99495 & 11.789 & $\begin{array}{c}2.016 \\
(0.05)(44)\end{array}$ & 0.000 \\
\hline
\end{tabular}

Table (3): Comparison between Pretest and posttest of performance skill according to their gender for control group.

\begin{tabular}{|c|c|c|c|c|c|c|c|c|}
\hline \multirow{2}{*}{ Gender } & \multirow{2}{*}{ No. } & \multicolumn{3}{|c|}{ Mean } & \multirow{2}{*}{ Sta. Dev. } & \multirow{2}{*}{ T cal. } & \multirow{2}{*}{ T tab. } & \multirow{2}{*}{ Sig. } \\
\hline & & Pre & Post & Deferens & & & & \\
\hline Male & 15 & 22.4667 & 23.6000 & 1.1333 & 5.13902 & 0.854 & $\begin{array}{c}2.145 \\
(0.05)(14)\end{array}$ & 0.407 \\
\hline Female & 30 & 24.0667 & 25.9000 & 1.8333 & 6.17606 & 1.626 & $\begin{array}{c}2.045 \\
(0.05)(29)\end{array}$ & 0.115 \\
\hline Total & 45 & 23.5333 & 25.1333 & 1.6000 & 5.80125 & 1.850 & $\begin{array}{c}2.016 \\
(0.05)(44)\end{array}$ & 0.071 \\
\hline
\end{tabular}


Table (4): Anxiety level of pretest and posttest for experimental group.

\begin{tabular}{||l|c|c|c|c|c|c|c|c||}
\hline \multirow{2}{*}{ Anxiety level } & \multicolumn{2}{|c|}{ pre simulation } & \multicolumn{2}{c|}{ Post simulation } & \multicolumn{2}{c|}{ Pre Patient } & \multicolumn{2}{c|}{ Post Patient } \\
\cline { 2 - 12 } & No. & $\mathbf{\%}$ & No. & \% & No. & \% & No. & \% \\
\hline Very Confident & 3 & 6.7 & 4 & 8.9 & 2 & 4.4 & 2 & 4.4 \\
\hline Confident & 5 & 11.1 & 5 & 11.1 & 4 & 8.9 & 5 & 11.1 \\
\hline Neutral & 29 & 64.5 & 30 & 66.7 & 9 & 20 & 7 & 15.6 \\
\hline Anxious & 6 & 13.3 & 4 & 8.9 & 26 & 57.8 & 28 & 62.2 \\
\hline Very Anxious & 2 & 4.4 & 2 & 4.4 & 4 & 8.9 & 3 & 6.7 \\
\hline Total & 45 & 100 & 45 & 100 & 45 & 100 & 45 & 100 \\
\hline
\end{tabular}

Table (5): Anxiety level of pretest and posttest for the study samples. $N=90$

\begin{tabular}{|l|c|c|c|c|c|c|c|c||}
\hline \multirow{2}{*}{ Anxiety level } & \multicolumn{2}{|c|}{ pre simulation } & \multicolumn{2}{c|}{ Post simulation } & \multicolumn{2}{c|}{ Pre Patient } & \multicolumn{2}{c|}{ Post Patient } \\
\cline { 2 - 10 } & Male & female & male & female & male & female & male & female \\
\hline Very Confident & 1 & 2 & 1 & 3 & 1 & 1 & 1 & 1 \\
\hline Confident & 2 & 3 & 2 & 3 & 2 & 2 & 2 & 3 \\
\hline Neutral & 10 & 19 & 11 & 19 & 3 & 6 & 2 & 5 \\
\hline Anxious & 2 & 4 & 1 & 3 & 7 & 19 & 9 & 19 \\
\hline Very Anxious & 0 & 2 & 0 & 2 & 2 & 2 & 1 & 2 \\
\hline Total & 15 & 30 & 15 & 30 & 15 & 30 & 15 & 30 \\
\hline
\end{tabular}

\section{DISCUSSION}

Nursing education is experiencing a generational phenomenon with student enrollment spanning three generations and many students returning to school already possessing a previous bachelor's degree. Generation $X$, and Generation $Y$ students are creating a very different culture in the classroom. Many of these students are non-traditional in that they have already obtained a bachelor's degree and are returning to school for various reasons such as desire for career change and a declining economy where other jobs may be difficult to find.

This raises questions about the value of investing in expensive simulation modalities when the increased costs associated with high fidelity manikins may not be justified by a concomitant increase learning outcomes. While these results should be factored into decisionmaking by those investing in simulated learning environments, they do need to be considered with a degree of caution as the study also raised questions about the appropriateness of using MCQs as a method of assessing the effectiveness of simulation experiences. Although the most common form of assessment in undergraduate nursing programs, few academics have adequate experience and training in developing quality MCQs (Tarrant et al., 2006). Based on demographic cultural factors of generational type and previous degree, to what extent, if any, do nursing pre-simulation, post-simulation, and post-clinical self-efficacy scores differ between students exposed to virtual clinical excursion
(VCE) and human patient simulation (HPS)? The results of the ANCOVAs revealed that none of the main effects (i.e., simulation type, generation, and degree type) were significant for any of the GSE change scores. Among the interaction effects tested, only one proved to be significant. The findings are discussed below. The results of the data analysis found many significant findings in the scores on the various subscales of the IMI. Since the subscales used in this study interest enjoyment, perceived competence, effort importance, pressure tension, and value usefulness are noted as the self-report measure of intrinsic motivation, these results are especially important to educators. The first assumption of Knowles's and Ragogical theory of adult learning is that adults need to understand the relevance of learning, and they learn best when information can be applied to real-life experiences (Knowles , 1990). The value usefulness subscale of the IMI measures the learner's perception of the value and usefulness of an activity. In this study, all groups who experienced the HPS simulation (generation X, generation Y, students with no previous degree, students with a previous associate or technical degree, and students with a previous bachelor's degree or higher) had significantly higher scores on the value/usefulness subscale of the IMI. In addition, all group mean scores for students experiencing the HPS simulation were above 6.50 on a Lickert scale from 1-7, indicating that these groups of students found this simulation activity to be particularly valuable and useful. To 
understand the significance, one may look at the mean group scores of those students exposed to the VCE simulation experience. The highest group mean score on the value, usefulness subscale was associated with students with no previous degree. Their mean group score was only 5.01, significantly lower than the scores presented by the HPS groups. When a learner finds an activity to be valuable and useful, it is likely that the learner will spend more effort on and place emphasis on the importance of doing well on that activity. Social cognitive theory is based on the notion that individuals proactively engage in their own development and are able to determine personal outcomes by the actions they take (Pajares , 2002). When a learner perceives the importance of putting effort into doing a task well, they are actively engaging in their own learning. No significant differences were found in the group scores on the effort/important subscale of the IMI, however, it should be noted that all groups (both HPS and VCE) scored above a 5.26 on a 1 to 7 scale on this subscale. In fact, the total group mean score was 5.88, indicating that the entire group found it important to place effort into performing this task well. The second assumption of Knowles's and ragogical theory of adult learning implies that adults need to be responsible for their own learning and decisions (Knowles , 1990). The perceived choice subscale of the IMI measures the learner's perception of their choice to complete the task at hand; in this study it was the simulation experience (HPS or VCE). Adults will have a stronger desire to learn and will choose to learn when they have a need or interest to learn. They are often motivated by internal pressures and in this time of economic crisis and high unemployment rates, adult learners realize that the time to learn is now. All groups who experienced the HPS simulation had significantly higher scores on the interest/enjoyment IMI subscale. This indicates a higher level of interest and enjoyment in the HPS activity over the VCE activity. In addition, all HPS groups (with the exception of the associate or technical degree student) showed significantly higher scores on the pressure/tension subscale of the IMI. Due to reverse scoring, higher scores on the pressure/tension subscale indicated less pressure and tension. Since pressure and tension are considered to be negative predictors of intrinsic motivation, it is desirable to have lower scores for this subscale. The perceived competence subscale of the IMI assessed the group's perception of how well they achieved the task given to them (HPS or VCE experience) (Bandura ,1986) . self-reflection is a characteristic that is unique to humans and allows for reflection of themselves, their capabilities, and on experiences allowing for the development of new knowledge. When a learner is able to positively reflect on an experience and their actions during that experience, the learner is likely to remember and learn more from the experience. In addition, a positive experience will increase self-efficacy. The results of this study indicated that students in the VCE exercise tended to feel more competent while performing simulation than those in the HPS group. Significant increases in perceived competence scores were seen in both generation $\mathrm{Y}$ and students with no previous degree. One possible explanation for this significant finding is that most of the students with no previous degree are from the generation $\mathrm{Y}$ age group. This group of students, known as digital natives, has spent their entire lives around computers and videogames (Rothgeb , 2008). They are accustomed to the rapid sensory stimulation and may feel more comfortable with computer-based simulation. When looking at the overall mean scores of the groups on the IMI, all groups of students who participated in the HPS simulation experience had average group scores higher than those students who participated in the VCE simulation experience. Significance was found at all levels and in all groups $(\mathrm{p}<0.001)$. This is an important finding because, along with most of the other individual IMI subscales, the HPS simulation activity may be identified as a more appropriate and motivating learning environment for all students. In a time where cost versus educational benefits is a point of discussion, noting that groups in the HPS simulation experience scored significantly higher on the IMI mean score than the groups in the VCE helps to justify the cost of the equipment. In addition, this finding begins the dialogue of the appropriateness of simulation for the various students from different cultural demographic areas because it confirms that HPS is appropriate for all groups, despite cultural demographics (group mean score 5.13 in HPS group versus 4.09 in VCE group).

\section{Human Patient Simulation vs Virtual Clinical Excursion}

An examination of the means of GSE scores revealed that among subjects with the midlevel degree type (i.e., associate or technical degree), those who were given the HPS simulation experience exhibited a substantially higher mean gain in GSE between the first two 
assessments than did those experiencing the VCE simulation experience. What is interesting to note is that students with no previous degree exhibited more gain in GSE scores when given the VCE experience rather than the HPS experience while students in the bachelor's degree or higher group exhibited more gain in GSE scores when given the HPS experience instead of the VCE experience. Each of these findings is discussed in further detail below. Students with the midlevel degree type (i.e., associate or technical degree) who were given the HPS simulation experience exhibited a substantially higher mean gain in self-efficacy between the first two assessments than did those experiencing the VCE simulation. In addition, students in the bachelor's degree or higher group exhibited more gain in GSE scores when given the HPS experience instead of the VCE experience, although the scores were not as substantially high as in the associate or technical degree group. In general, second-degree students tend to be older (range 28-40 years) than traditional BSN students (Toth et al .,1998); Wu \& Connelly, 1992. With this age range, one can assume that the majority of the students in this study were classified as generation $\mathrm{X}$ students and adult learners. (Bandura ,1986) defined selfefficacy as -people's judgments of their capabilities to organize and execute courses of action required to attain designated types of performances (p.391). The same person may perform very differently on the same task on different occasions based on their self-efficacy at the time the task was completed. In fact, (Bandura,1997) contends -people's level of motivation, affective states, and actions are based more on what they believe than on what is objectively truell (p. 2). Generation X students expect the use of technology in the classroom along with instant response and satisfaction (Johnson \& Romanello, 2005). They have little regard for wasted time or non-relevant information (Coates, 2007) These students bring with them various previous life experiences that they draw upon when in the simulation setting. Human patient simulation allows the learners to utilize hands-on technology in the classroom environment while providing instant feedback. It is fast-paced with each moment being utilized as a teaching/learning moment. Students work in groups and are able to learn by using their own life experiences and by watching the experiences of others. By symbolically coding information learned from observation of others, individuals can often learn and avoid mistakes without actually having to perform an action (Pajares,
2002). Since reported self-efficacy was based on the clinical objectives for nurse, it is not unexpected that second degree students exhibited higher self-efficacy scores after participating in human patient simulation, especially when one considers the extent of previous social and academic life skills that this group possessed and was able to utilize in the interactive group simulation learning experience.

The virtual clinical excursion is very similar to a clinical videogame in that the student essentially plays out a clinical scenario by inputting data into a computer using a keyboard and mouse. These students tend to have limited life experiences that they are able to draw upon when working on group activities. They have a preference for learning on their own time and also on their own terms (McGlynn, 2005).

The findings show that the simulation technique in the peripheral venous catheterization in pediatric patients leads to a significant increase in self-confidence of students compared to the traditional method of demonstration.

In a study that applied by Kaddoura on ten recently graduated nursing students showed that students who were trained through simulation method, had more confidence in the care of patients. (Kaddoura, 2010). New graduate nurses' perceptions of (Thomas and Mackey, 2012). Also showed significant increase in confidence scores in aspects of diagnosis and symptoms, patient assessment, nursing, and evaluating in comparison with the traditional method group. (Thomas and Mackey, 2012).

In addition (Tiffen et al., 2009). Shows that 32 nursing students of advanced performance level, self-confidence of students who were trained cardiovascular assessment through simulation increased significantly compared to the group who were trained by lecture and using models. (Tiffen et al ., 2009).

Moreover, in a study conducted by Brown and Chronister, a significant improvement was noted in the self-confidence of nursing students who were trained electrocardiogram course through simulation in addition to lecture compared to those who only received training through lectures. (Brown and Chronister,2009).

The results of the above mentioned studies confirm the findings of the present research, and indicate the effect of simulation method on increased self-confidence of nursing students in carrying out procedures. However, these studies did have some limitations. For example, (Tiffen et al.,2009) Did not assess demographic 
characteristics before the intervention, the congruity of the nursing students about their experiences of cardiopulmonary assessment was not determined, they did not include a pre-test, and their instruments were made by the researcher. In the research by (Brown and Chronister, 2009). the applied data collection instruments were also self-made. Another point is that the validity of the instruments had not been determined which reduced validation and generalizability of the results. However, in the research by Brannan et al., no significant difference was seen between self-confidence of the students who were trained acute myocardial infection through simulation compared to those who were trained by lecture. ( Brannan, et al., 2008).

In addition, the findings of the Soucy research of (49) nursing students did not indicate a significant difference in the self-confidence of students who were trained, caring for pediatric patients through simulation, compare to those trained through the traditional method. (Soucy, 2011).

The cause of the variation of these findings with the present study could be the type of study, realistic of tools and training method. As stated previously, nursing students are generally anxious at the beginning of the internship, because practice needs more skills and more delicate than theory (Linder and Pulsipher, 2008).

In addition, parents are usually present at the bedside. Simulation in pediatric clinical nursing education allows students to actively learn and develop confidence in pediatric nursing care without the fear of putting the patient at risk and being scrutinized by the parents. Better judgment can be made about the demonstration method with a greater sample size. (Harris, 2011).

\section{REFERENCES}

Bandura, A. (1986). Social foundations of thought and action: A social cognitive theory. Englewood Cliffs, NJ: PrenticeHal. USA.

Bandura, A. (1997). Self-efficacy: The exercise of control. Freeman and Company. New York. USA.

Brannan, JD.; White, A.; and Bezanson, JL. (2008). Simulator effects on cognitive skills and confidence levels. Journal of Continue Nursing Education. 47. P.p.495500.
Brown, D.; and Chronister, C. (2009). The effect of simulation learning on critical thinking and self-confidence when incorporated into an electrocardiogram nursing course. Clinical Simulation in Nursing. 5. P.p.e45e52.

Coates, J. (2007). Generational learning styles. River Falls: Lern Books.

Garrett, B.; Macphee, M.; Jackon, C. (2010). High-Fidelity patient simulation: consecration for effective learning. Nursing Education perspectives. 31. P.p. 309-313.

Harris, MA. (2011). Simulation-enhanced pediatric clinical orientation. Journal of Continue Nursing Education. 50. P.p.461465.

Johnson, S.; and Romanello, M. (2005). Generational diversity: Teaching and learning approaches. Nurse Educator; 30. P.p.212-216.

Kaddoura, MA. (2010). New graduate nurses' perceptions of the effects of clinical simulation on their critical thinking, learning, and confidence. Journal of Continue Nursing Education. 41. P.p.506516.

Knowles, M. (1990). The adult learner: A neglected species. ( $4^{\text {th }}$ ed.) Gulf Publishing Company. Houston. USA.

Linder, LA.; and Pulsipher, N. (2008). Implementation of Simulated learning experiences for baccalaureate pediatric nursing students. Clinical Simulation in Nursing. 4. P.p.e41-e47.

McGlynn, A. (2005). Teaching millennials, our newest cultural cohort. The Hispanic Outlook in Higher Education. 16: 19-20.

National Council of State Broads of Nursing. (2009). The effect of high-fidelity simulation on nursing students' knowledge and performance: A pilot study. NCSBN Research Brief. 40. P.p. 1-27.

Pajares, F. (2002). Overview of social cognitive theory and of self-efficacy. Online Journal of Nursing Education Today 2007. [Online]. http://www. NeDJT.edu/SCTandSIM/mfp/eff.html.

Partin, JL.; Payne, TA.; Slemmons, MF. (2006). Students' perception of their learning experiences using high-fidelity simulation to teach concepts relative to obstetrics. Nursing Education Perspectives. 32. P.p. 186-188. 
Rothgeb, M. (2008). Creating a nursing simulation laboratory: A literature review. Thorofare. 47. P.p.489-494.

Soucy, EC. (2011). The effects of high-fidelity simulators on nursing students' critical thinking and self-confidence [dissertation]. Prescott Valley, AZ: North central University.

Tarrant M.; Knierim, A.; Hayes, S.; and Ware, J. (2006). The frequency of item writing flaws in multiple choice questions used in high stakes nursing assessments. Nurse Education Today. 26. P.p. 662-671.

Thomas, C. Mackey, E. (2012). Influence of a clinical simulation elective on baccalaureate nursing student clinical confidence. Journal of Continue Nursing Education. 51. P.p.236-239.
Tiffen, J.; Graf, N.; and Corbridge, S. (2009). Effectiveness of a low-fidelity simulation experience in building confidence among advanced practice nursing graduate students. Clinical Simulation in Nursing. 5. P.p.e113-e117.

Toth, J.; Dobratz, M.; Boni, M. (1998). Attitude toward nursing of students earning a second degree and traditional baccalaureate students. Nursing Outlook. 46. P.p. 273-278.

Yuan, HB. Williams, BA.; Fang, JB. (2011). Contribution of high - fidelity simulation to nursing students' confidence and competence: a systematic review. International Nursing Review. 3. P.p. 2633. 